\title{
Growth activation of influenza virus by trypsin and effect of T-705 (favipiravir) on trypsin-optimized growth condition
}

\author{
T. DAIKOKU ${ }^{1}$, T. OKUDA², M. KAWAI², N. MORITA², T. TANAKA ${ }^{3}$, M. TAKEMOTO ${ }^{1}$, Y. FUKUDA ${ }^{3}$, \\ K. TAKAHASHI ${ }^{3}$, N. NOMURA ${ }^{3}$, K. SHIRAKI ${ }^{2}$
}

\begin{abstract}
${ }^{1}$ Laboratory of Microbiology and Immunology, Faculty of Pharmaceutical Sciences, Hokuriku University, 3 Ho, Kanegawa, Kanazawa, 920-1181, Japan; ${ }^{2}$ Department of Virology, University of Toyama, 2630 Sugitani, Toyama 930-0194, Japan; ${ }^{3}$ Research Laboratories, Toyama Chemical Co., Ltd., 2-4-1 Shimookui, Toyama 930-8508, Japan
\end{abstract}

Received March 20, 2018; revised September 4, 2018; accepted December 19, 2018

\begin{abstract}
Summary. - Influenza virus is activated by proteolytic cleavage of hemagglutinin by trypsin. After determining the optimal trypsin concentration, intracellular and extracellular influenza A/PR/8/34 (H1N1) and A/ Victoria/361/2011 (H3N2) virus productions were compared in cultures treated with T-705 (favipiravir) and GS 4071 (an active form of oseltamivir). Although both drugs efficiently inhibited extracellular viral RNA release in a dose-dependent manner, T-705 inhibited it to the level of the inoculum without trypsin treatment, while GS 4071 inhibited it to a final level 10 times higher than that without trypsin. T-705 inhibited intracellular viral RNA production to the level of input virus in both trypsin-treated and untreated cells. In contrast, GS 4071 dosedependently inhibited intracellular viral RNA production in cells treated with trypsin but allowed viral RNA synthesis. The level of maximum inhibition by GS 4071was 10 times higher than that of cells without trypsin and 1,000 times greater than the inoculum titer in cells without trypsin. T-705 inhibited both intracellular and extracellular virus production 1,000 and 10 times more strongly, respectively, than GS 4071. T-705 has powerful anti-influenza activity in the absence of trypsin and even in the trypsin-optimized growth condition, suggesting the therapeutic advantage in treatment of influenza complicated with bacterial pneumonia.
\end{abstract}

Keywords: influenza; T-705; Tamiflu; trypsin; bacterial trypsin-like protease

\section{Introduction}

T-705 (favipiravir, 6-fluoro-3-hydroxy-2-pyrazinecarboxamide) shows a novel anti-influenza virus activity in vitro and in vivo by inhibiting viral RNA synthesis (Takahashi et al., 2003; Furuta et al., 2002, 2005, 2009; Sangawa et al., 2013; Daikoku et al., 2014;). It inhibits the replication of the avian influenza H5N1 virus (Sidwell et al., 2007; Smee et al., 2009) and exhibits therapeutic activity against the highly pathogenic avian influenza $\mathrm{H} 5 \mathrm{~N} 1$ virus (HPAI) infection in mice (Sidwell et al., 2007; Smee et al., 2009; Kiso et al., 2010). T-705 inhibits viral RNA-dependent RNA polymerase

E-mail: t-daikoku@hokuriku-u.ac.jp; phone: +81-76-434-7255.

Abbreviations: $\mathrm{IC}_{50}=50 \%$ inhibition concentration; $\mathrm{MOI}=$ multiplicity of infection; TLP(s) = trypsin or bacterial trypsin-like protease (s) by inhibiting elongation at the incorporated site as a purine analog (Furuta et al., 2005; Sidwell et al., 2007; Jin et al., 2013; Sangawa et al., 2013) and a chain terminator. Thus, T-705 is a promising drug for treatment of influenza virus infections, including severe seasonal influenza virus infection and HPAI infection in humans. T-705 and oseltamivir show similar therapeutic effects against mild influenza infection in mice. However, T-705 prevented death of mice infected with a high dose of intranasal influenza virus, while oseltamivir only delayed it (Takahashi et al., 2003). Thus, T-705 seemed to be more effective than oseltamivir in the alleviation of influenza infection in animal models.

The hemagglutinin of influenza virus is cleaved and activated for fusion by trypsin or bacterial trypsin-like proteases (TLPs), and this is essential for influenza virus growth in vitro and in vivo (Tashiro et al., 1987a,b). Tryptase Clara is responsible for increasing the infectivity of influenza virus 
in the airways (Kido et al., 1992). Supplementation with TLP from Staphylococcus aureus in influenza-infected mice enhances influenza virus growth in the lungs and causes development of severe influenza pneumonia but not bacterial pneumonia (Tashiro et al., 1987a,b). When virus from lungs was treated with trypsin without $S$. aureus, the virus titer was increased at least 10 times in the lungs by trypsin treatment, indicating the virus in the lungs was not fully activated by TLP. Thus, the presence of bacterial TLP or trypsin is important for influenza virus to acquire growth capability and cause severe pneumonia.

Neuraminidase inhibitors show therapeutic activity by inhibiting the release of virus particles from infected cells, but they do not inhibit intracellular virus production. T-705 specifically inhibits viral RNA synthesis and thereby inhibits viral replication and production (Furuta et al., 2002, 2005, 2009; Takahashi et al., 2003) .

To date, the anti-influenza virus activities of T-705 and oseltamivir have been compared at the conventional trypsin concentration. Here we compared the effects of T-705 and GS 4071, an active form of oseltamivir, on virus growth enhanced by the optimized trypsin conditions to evaluate the differential inhibitory mechanisms of action on influenza virus growth and found a significant difference in their anti-influenza effects that had not been observed with the conventional concentration of trypsin in a comparison of anti-influenza activities of T-705 and GS 4071. This study was designed to clarify the difference between anti-influenza activities of the two drugs in the trypsin-optimized conditions, and demonstrated a striking difference in T-705 and oseltamivir. T-705 was significantly more effective in inhibiting extracellular virus and intracellular viral RNA production in influenza virus-infected cultures than GS 4071, in the absence of trypsin and even in optimized trypsin concentration conditions.

\section{Materials and Methods}

Cells and viruses. Madin-Darby canine kidney (MDCK) cells were grown and maintained in Eagle's minimum essential medium supplemented with $5 \%$ and $2 \%$ heat-inactivated calf serum, respectively. Influenza A/PR/8/34 (H1N1) virus and A/Victoria/361/2011 $(\mathrm{H} 3 \mathrm{~N} 2)$ virus were propagated in MDCK cells in the presence of $2.5 \mu \mathrm{g} / \mathrm{ml}$ trypsin and stored at $-80^{\circ} \mathrm{C}$ until use (Kurokawa et al., 1996, 2009; Furuta et al., 2002). A/Victoria/361/2011 (H3N2) virus was obtained from the National Institute of Health Sciences, Japan. Trypsin-free influenza virus was prepared as follows. MDCK cells were infected with 0.01 plaque-forming units (PFU) per cell and incubated in the medium containing $3.5 \mu \mathrm{g} / \mathrm{ml}$ of trypsin for $24 \mathrm{~h}$. Then the infected cells were washed three times with medium containing $5 \%$ calf serum to remove and inactivate trypsin, and incubated in the medium containing $1 \%$ bovine serum albumin (BSA) for $24 \mathrm{~h}$. The culture was frozen and thawed three times, followed by centrifugation at $3,000 \mathrm{rpm}$ for $10 \mathrm{~min}$. The supernatant was used as trypsin-free virus. Virus titer was determined by a plaque assay using agarose medium containing $1.5 \mu \mathrm{g} / \mathrm{ml}$ of trypsin after fixation with neutral formalin and staining with methylene blue (Kurokawa et al., 1996, 2002, 2010; Tsurita et al., 2001).

Compounds. T-705 and GS 4071, an active form of oseltamivir, were synthesized at Toyama Chemical Co., Ltd. (Toyama, Japan). T-705 and GS 4071 were dissolved in the medium for in vitro assays. The $50 \%$ inhibition concentrations $\left(\mathrm{IC}_{50}\right)$ of influenza $\mathrm{A} / \mathrm{PR} / 8 / 34$ virus by T-705 and GS 4071 are 0.16 and $0.0039 \mu \mathrm{g} / \mathrm{ml}$, respectively (Furuta et al., 2002, 2005). TPCK-treated trypsin from bovine pancreas was purchased from Takara Bio Inc. (Shiga, Japan).

Effects of trypsin on influenza virus production in cells infected with trypsin-free virus. MDCK cells in 24-well culture dishes were washed with medium and infected with aliquots $(100 \mu \mathrm{l})$ of $100 \mathrm{PFU}$ of A/PR/8/34 (H1N1) or $100 \mathrm{PFU}$ of A/Victoria/361/2011 (H3N2) virus for $1 \mathrm{~h}$ at room temperature. After washing the cells with medium to remove unadsorbed virus, the cells were incubated with $0.5 \mathrm{ml}$ of medium containing $3 \mu \mathrm{g} / \mathrm{ml}$ trypsin for A/PR/8/34 (H1N1) virus and $1 \mu \mathrm{g} / \mathrm{ml}$ trypsin for A/Victoria/361/2011 (H3N2) virus for $24 \mathrm{~h}$, as the optimal conditions for each virus replication, in the presence of various concentrations of T-705 and GS 4071. Productions of intracellular and extracellular viral RNA were determined by harvesting and extracting RNA from the cellular fractions and culture supernatants.

Extraction of viral RNA and determination of amount of viral $R N A$. Culture supernatants $(200 \mu \mathrm{l})$ after centrifugation and total cellular fractions suspended in $200 \mu \mathrm{l}$ of MEM were used for RNA extraction using a High Pure Viral RNA kit (Roche Diagnostics, Mannheim, Germany) according to the manufacturer's protocol. Reverse transcription (RT) was carried out by Reva-TraAce kit (Toyobo Bio, Osaka, Japan) using an influenza viral RNA-specific primer Uni12 (5'-AGCGAAAGCAGG-3') in a $10-\mu \mathrm{l}$ reaction mixture at $37^{\circ} \mathrm{C}$ for $1 \mathrm{~h}$. Two microliters of the RT reaction mixture were then used for real-time PCR by using an influenza M gene-specific primer set, forward primer (5'-CGCTCAGACATGAGAACAGAATGG-3'), and reverse primer (5'-TAACTAGCCTGACTAGCAACCTC-3') in SYBR green PCR Master Mix (Kapa Biosystems, Cape Town, South Africa). Before the quantitative PCR, the mixture was incubated at $95^{\circ} \mathrm{C}$ for $10 \mathrm{~min}$. The quantitative PCR reaction was performed at $95^{\circ} \mathrm{C}$ for $10 \mathrm{~s}, 57^{\circ} \mathrm{C}$ for $20 \mathrm{~s}$, and $72^{\circ} \mathrm{C}$ for $30 \mathrm{~s}$ for $45 \mathrm{cycles}$, and the levels of PCR products were monitored with a Takara Dice thermal cycler for real-time PCR system and analyzed with Takara Real-time PCR software (Takara Bio Inc., Otsu, Shiga, Japan). The RNA copy numbers of the $\mathrm{M}$ gene were expressed as copies $/ \mathrm{ml}$ in the reaction mixtures. For standard curve, the amplified $M$ gene was purified and the calibration curve was prepared as a 10-fold dilution series from $10,000,000$ copies/ $\mu$, so that the observed range of quantitation cycle $(\mathrm{Ct})$ values covered that obtained for all experimental samples.

Statistical analyses. Concentration-dependent effects of T-705 and GS 4071 on RNA copy numbers were analyzed by the two-factor factorial analysis of variance (ANOVA). A P value of less than 0.05 was defined as statistically significant. 


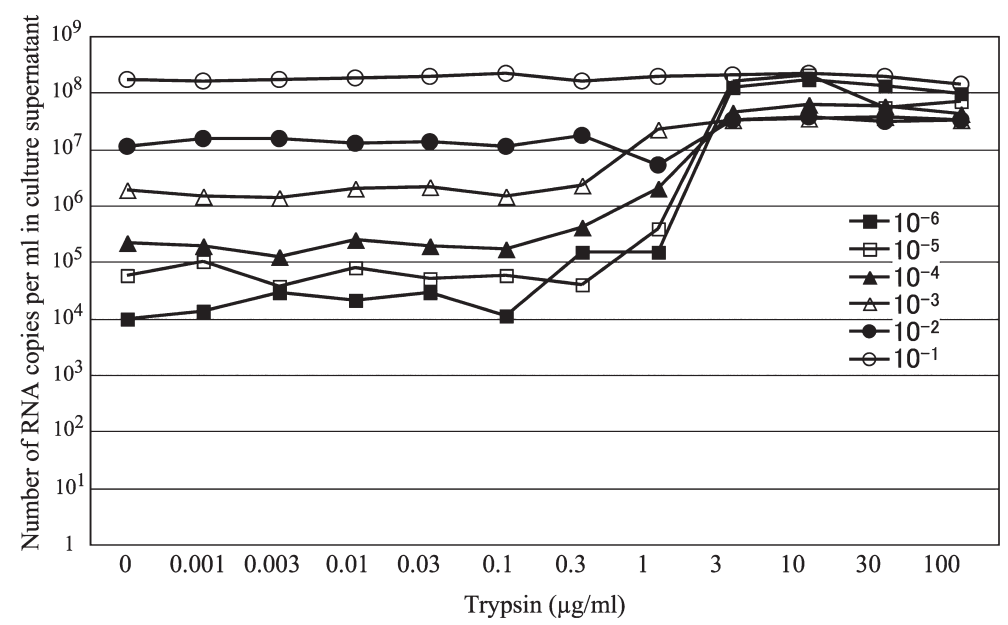

Fig. 1

Effects of trypsin concentration and multiplicity of infection on A/PR/8/34 (H1N1) virus yield as assessed by RNA copy number of the M gene in culture supernatants

Trypsin concentrations ranged from 0 to $100 \mu \mathrm{g} / \mathrm{ml}$, and the MOI ranged from $10^{-1}$ to $10^{-6} \mathrm{PFU} / \mathrm{cell}$.

\section{Results}

Effects of trypsin concentration on trypsin-free influenza virus growth

The effects of trypsin were evaluated by the production of $\mathrm{A} / \mathrm{PR} / 8 / 34$ (H1N1) virus in the culture medium. Viral yields assessed by the RNA copy number of the $M$ gene in the culture supernatants were dependent on the trypsin concentration and multiplicity of infection (MOI), as shown in Fig. 1. When the MOI was 0.1 PFU/cell or higher, RNA copy number may be saturated and trypsin concentration had little effect. When the MOI was lower than 0.001 PFU/ cells, RNA production increased at $1 \mu \mathrm{g} / \mathrm{ml}$ of trypsin and saturated at $3 \mu \mathrm{g} / \mathrm{ml}$. The virus yield increased concentrationdependently up to the trypsin concentration of $3 \mu \mathrm{g} / \mathrm{ml}$ at a low MOI and was saturated at the trypsin concentration of $3 \mu \mathrm{g} / \mathrm{ml}$ and higher.

Trypsin concentrations for A/Victoria/361/2011 (H3N2) virus were similar to those for $\mathrm{A} / \mathrm{PR} / 8 / 34(\mathrm{H} 1 \mathrm{~N} 1)$ virus, and the virus yield was saturated at the trypsin concentration of $1 \mu \mathrm{g} / \mathrm{ml}$ and higher (data not shown). Because we assessed the virus yields by RNA copy number rather than by infectivity, there may be discrepancies of trypsin-dependency between them in the virus yields. Thus, trypsin at concentrations of 3 and $1 \mu \mathrm{g} / \mathrm{ml}$ and higher concentration for $\mathrm{A} / \mathrm{PR} / 8 / 34$ (H1N1) virus and A/Victoria/361/2011 (H3N2) virus, respectively, were suitable for assessing the effects of T-705 and GS 4071 on the growth of influenza virus in trypsin-optimized growth conditions.
Effects of T-705 and GS 4071 on intracellular viral RNA production and virus production into extracellular fractions in the trypsin-treated cultures

Influenza virus growth was optimized by the trypsin concentration and in these conditions the anti-influenza activity of T-705 and GS 4071 were compared at various concentrations as shown in Fig. 2. Figure $2 \mathrm{a}$ shows the differential inhibitory activities of T-705 and GS 4071 on the A/PR/8/34 virus yields (RNA copy number) of the extracellular fractions in cultures treated with the optimized concentration of trypsin. Viral RNA release into the culture supernatants was not increased in influenza virus-infected extracellular fractions without trypsin treatment. T-705 inhibited viral RNA release starting at the concentration of $0.32 \times \mathrm{IC}_{50}$, and at the concentration of $3.2 \times \mathrm{IC}_{50}$ it inhibited the release to the level with and without trypsin treatment. GS 4071 inhibited viral RNA release from the concentration

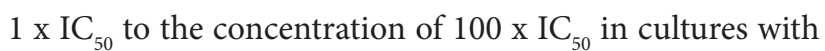
trypsin treatment and treatment with GS 4071 did not inhibit to the level without trypsin treatment. Both T-705 and GS 4071 inhibited the RNA release in the culture medium and T-705 inhibited it more efficiently than GS 4071. When the cultures were not treated with trypsin, T-705 significantly reduced viral RNA release but GS 4071 did not.

Figure $2 \mathrm{~b}$ shows anti-influenza activity of T-705 and GS 4071 in infected cellular fractions. RNA synthesis was increased in intracellular fractions without trypsin treatment but not as much as in those with trypsin treatment. Intracellular RNA synthesis was inhibited by T-705 but GS 4071 treatment did not reduce intracellular RNA synthesis. Viral RNA 
(a)

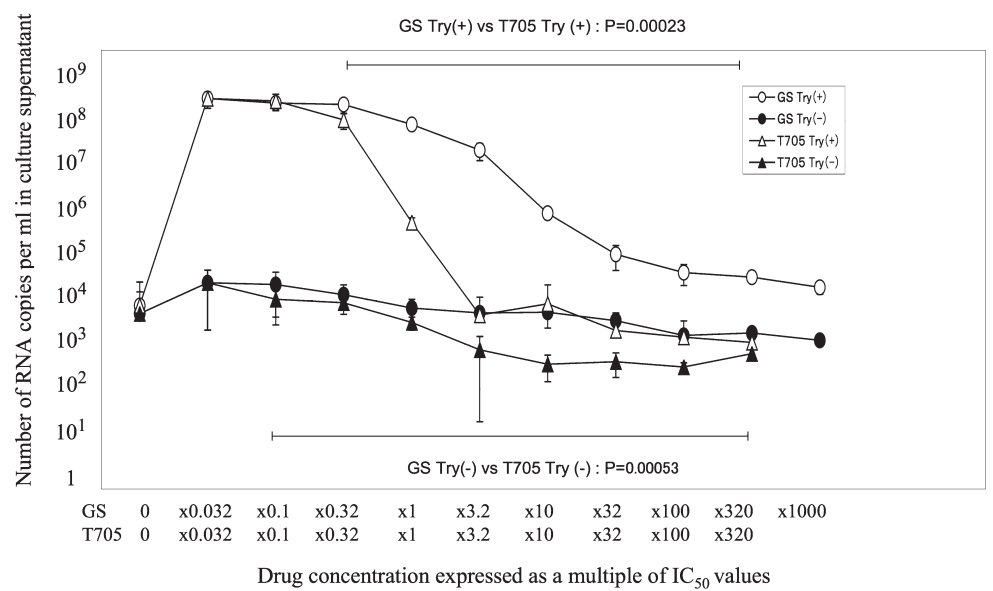

(b)

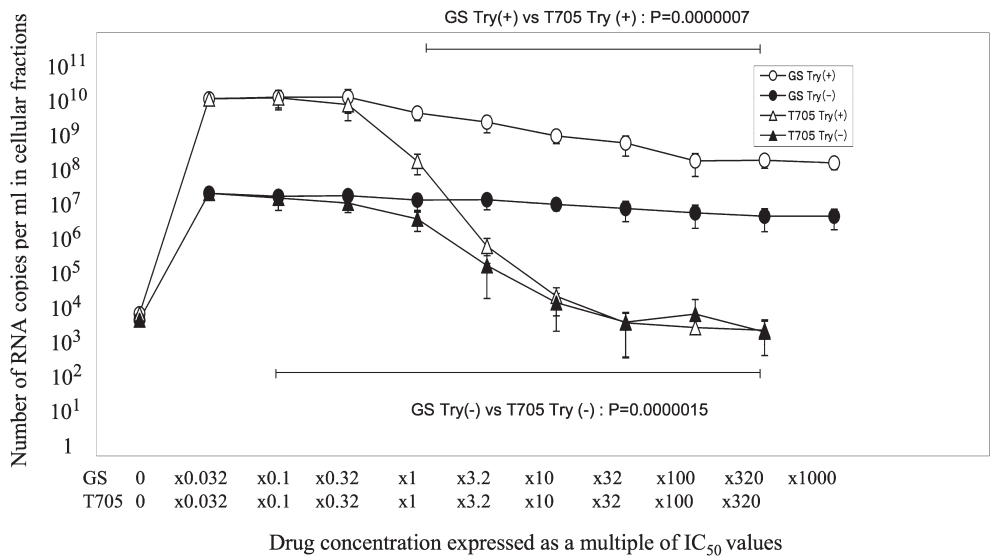

Fig. 2

Comparison of extracellular virus and intracellular viral RNA production of A/PR/8/34 (H1N1) virus yields between treatments with T-705 and GS 4071 in trypsin-optimized culture conditions or without trypsin as assessed by RNA copy number

Effects of T-705 and GS 4071 on virus growth were compared based on the $\mathrm{IC}_{50}$ concentration. The inhibitory activities of T-705 and GS 4071 on the profiles of extracellular virus release and intracellular viral RNA production yields are shown in figure (a) and (b), respectively. IC $\mathrm{I}_{50}$ values of A/PR/8/34 (H1N1) virus for T-705 and GS 4071 were 3 and $0.003 \mu \mathrm{g} / \mathrm{ml}$, respectively. RNA copy numbers of the M gene were expressed as the mean \pm SD of three samples. RNA copy numbers were compared in the ranges indicated by lines between T-705 and GS 4071 treatments in trypsin-treated and untreated groups, and the P values show significant differences versus GS 4071 treatment in the underlined range by the two-factor factorial ANOVA.

synthesis in cells treated with T-705 starting at the concentration of $0.32 \times \mathrm{IC}_{50}$, and at the concentration of $3.2 \times \mathrm{IC}_{50}$ was inhibited to the level without trypsin treatment. Inhibition of RNA synthesis by GS 4071 was limited and the suppression level was 10 times weaker than that without trypsin. Both drugs efficiently inhibited extracellular virus production in a dose-dependent manner. T-705 inhibited viral RNA synthesis as judged by the presence of viral RNA in both intracellular and extracellular fractions. GS 4071 inhibited production of viral RNA in the extracellular fraction, but RNA synthesis in the intracellular fraction was not inhibited. Thus the pattern of inhibition by T-705 and GS 4071 was different and presence of T-705 lead to significantly lower amounts of RNA copies than the presence of GS 4071, as underlined in the figures.
Figure 3 shows that the inhibition of of A/Victoria/361/2011 (H3N2) virus growth by T-705 and GS 4071 is similar to that of $\mathrm{A} / \mathrm{PR} / 8 / 34$ virus, as shown in Fig. 2. The trypsin concentration used for A/Victoria/361/2011 was $1 \mu \mathrm{g} / \mathrm{ml}$, lower than the $3 \mu \mathrm{g} / \mathrm{ml}$ used for $\mathrm{A} / \mathrm{PR} / 8 / 34$ virus and thus $\mathrm{A} /$ Victoria/361/2011 (H3N2) virus was more trypsin-sensitive than A/PR/8/34 virus. Figure 3a,b shows the effect of T-705 and GS 4071 on viral RNA release into the culture supernatant and production in infected cells, respectively, with or without trypsin treatment. T-705 inhibited the level of virus yields to the level of inoculums without trypsin treatment in Fig. 3a. GS 4071 inhibited the virus release into the culture supernatant dose-dependently, but the final inhibition of viral yields by GS 4071 was more 
(a)

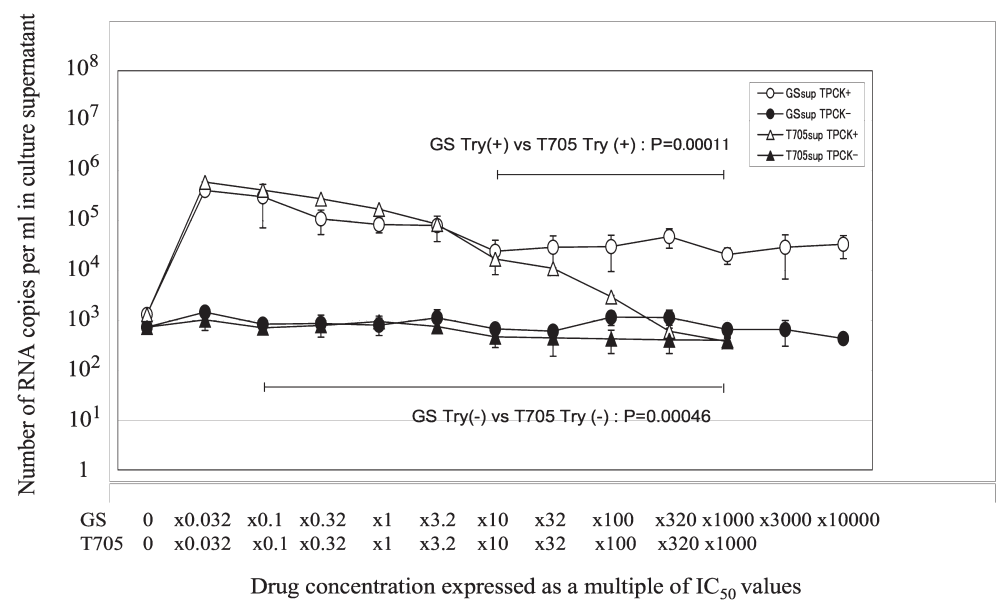

(b)

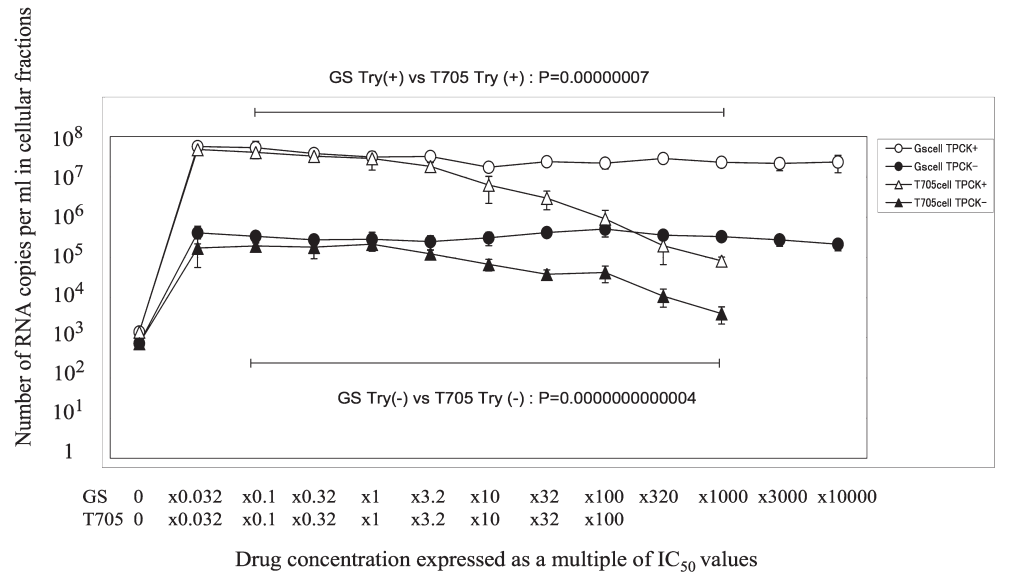

Fig. 3

Comparison of extracellular virus and intracellular viral RNA production A/Victoria/361/2011 (H3N2) virus yields between treatments with T-705 and GS 4071 in trypsin-optimized culture conditions or without trypsin as assessed by RNA copy number

Effects of T-705 and GS 4071 on virus growth were compared based on the $\mathrm{IC}_{50}$ concentration. The inhibitory activities of T-705 and GS 4071 on the profiles of extracellular virus yields and intracellular viral RNA production yields are shown in figure (a) and (b), respectively. IC ${ }_{50}$ values of A/Victoria/361/2011 (H3N2) virus for T-705 and GS 4071 were 3 and $0.3 \mu \mathrm{g} / \mathrm{ml}$, respectively. RNA copy numbers of the M gene are expressed as the mean \pm SD of three samples. RNA copy numbers were compared in the ranges indicated by lines between T-705 and GS 4071 treatments in trypsin-treated groups or trypsinuntreated groups, and the P values show significant differences versus GS 4071 treatment in the underlined range by the two-factor factorial ANOVA.

than 10 times higher than that without trypsin or those with T-705 treatments even at the highest concentration of GS 4071 used. This indicated that T-705 totally inhibited the release of the virus into the extracellular fraction but that GS 4071 allowed the virus production and release from the cells into the extracellular space at its high concentrations.

The difference between the anti-influenza actions of T-705 and GS 4071 was much more pronounced in the intracellular viral RNA production, as shown in Fig. 3b. Input virus produced $10^{6}$ intracellular viral RNA copies/ml even without trypsin, and trypsin treatment without a drug and at low concentrations of T-705 and GS 4071 enhanced the intracellular viral RNA production to $10^{8} \mathrm{RNA}$ copies $/ \mathrm{ml}$. T-705 dosedependently inhibited intracellular viral RNA production to the level of virus input in both trypsin-treated and untreated cells, indicating no viral growth after treatment with T-705. In contrast, GS 4071 allowed more than 100 times greater RNA production than the inoculum titer in cells without trypsin treatment, and intracellular viral RNA production was not inhibited by GS 4071 even at the highest concentration used. Intracellular viral RNA production in cells treated with and without trypsin was dose-dependently inhibited by T-705, but treatment of cells with GS4071 limited the inhibition of intracellular RNA production, resulting in the dissociation of the inhibition curve between T-705 and GS 4071. T-705 inhibited it to an intracellular viral RNA production (RNA copy number) 10,000 times lower than GS 4071 in cells with trypsin treatment, and the inhibition of viral RNA produc- 
tion by T-705 was similar to the amount of inoculated virus, indicating no viral RNA production in the infected cells.

Inhibition of extracellular viral RNA release and intracellular viral RNA productions by T-705 and GS 4071 were compared in the trypsin-optimized culture condition and without trypsin treatment. GS 4071 allowed intracellular viral RNA production but reduced the amount of extracellular viral RNA by inhibiting the virus release from infected cells and new infection of other cells, while T-705 inhibited both intracellular viral RNA production and extracellular virus production by inhibiting viral RNA synthesis.

\section{Discussion}

Secondary bacterial pneumonia is an important complication of influenza and contributes to approximately $25 \%$ of all influenza-associated deaths. Influenza virus affects the tracheobronchial epithelium, directly leading to a decrease in the size of cells and loss of cilia (Treanor., 2005). The most common bacterial pathogen is S. pneumoniae (Schwarzmann et al., 1971), and S. aureus, an increasingly common cause of community-acquired pneumonia, is the second most common (Bisno et al., 1971; Schwarzmann et al., 1971). When the incidence was compared in an epidemic year with a nonepidemic year for influenza, among community-acquired pathogens only $S$. aureus was significantly increased in the influenza epidemic year (Schwarzmann et al., 1971).

In a mouse model of the synergism between influenza virus and $S$. pneumoniae, the level of neuraminidase activity correlated with increased adherence and invasion of $S$. pneumoniae (Peltola et al., 2005). S. aureus has been shown to cause severe influenza pneumonia rather than bacterial pneumonia by its TLP activity (Tashiro et al., 1987a,b). S. aureus enhanced virus production in the lung by augmenting virus growth with the TLP supplied without causing bacterial pneumonia. The titer of influenza virus isolated from the lung coadministered with $S$. aureus was not changed in the assays in the presence or absence of trypsin, while that isolated from influenza virus alone was about 10 times higher in a trypsin-treated assay than in an trypsin-free assay. This indicated that influenza virus was fully activated in the lung by endogenous TLP with coadministration of $S$. aureus.

We have previously compared the anti-influenza virus activity of T-705 and GS 4071 against A/PR/8/34 (H1N1) virus and A/Victoria/361/2011 (H3N2) virus but never observed a difference between them in anti-influenza action, even in the presence of a conventional dose of trypsin. The attenuated anti-influenza action of GS 4071 compared to T-705 in the presence of trypsin was revealed for the first time by using the optimized condition of trypsin for virus growth in this study.

This study clarified the effects of trypsin on the growth of influenza virus as assessed by the quantitative RT-PCR of the influenza M gene. Based on the effects of trypsin on influenza virus growth, we characterized the anti-influenza effects of T-705 and GS 4071 on influenza virus growth in the presence or absence of trypsin as a representative TLP. Influenza virus failed to replicate in the absence of trypsin but did replicate in a trypsin concentration-dependent manner when it was present. Thus, trypsin had a crucially important effect on influenza growth, indicating the contribution of bacterial TLPs as described above.

When the effects of the anti-influenza drugs T-705 and GS 4071 on intracellular viral RNA production and extracellular influenza virus production were evaluated in the trypsin-optimized growth condition, T-705 and GS 4071 had strikingly different growth inhibition profiles in both intracellular viral RNA production and extracellular virus production, and the maximum inhibitions of virus yields attained by T-705 were 10 and 10,000 times, respectively, more effective than that by GS 4071. Although similar results were obtained in the action of T-705 and GS 4071 on the suppression of viral RNA release and viral RNA synthesis in the cultures infected with A/Victoria/361/2011 (H3N2) virus in Fig. 3, maximal growth was 100 times lower in A/ Victoria/361/2011 (H3N2) virus-infected cultures than in $\mathrm{A} / \mathrm{PR} / 8 / 34$ (H1N1) virus-infected cultures. The mode of inhibition by T-705 and GS 4701 was preserved in cultures infected with A/PR/8/34 (H1N1) and A/Victoria/361/2011 (H3N2) virus, but the extent of inhibition of RNA release and synthesis was different.

The difference between T-705 and GS 4071 in inhibiting influenza growth was due the difference in the mechanism of action, which is as follows. GS 4071 inhibits neuraminidase and the release of virus from infected cells, thereby inhibiting the spread of infection. In contrast, T-705 inhibits viral RNA synthesis and virus production in infected cells and thereby inhibits viral RNA release. These differences in the mechanisms of action caused the great difference in the conditions with optimized trypsin in this study. T-705 inhibited intracellular RNA synthesis in cells without trypsin and, in contrast, GS 4071 did not inhibit intracellular RNA synthesis. Thus the advantage of T-705 is inhibition of RNA synthesis in cells treated with and without trypsin and the level of inhibition in RNA synthesis and RNA release was larger in T-705 treatment than in GS 4071 treatment. Thus bacterial TLP or trypsin would not affect anti-influenza action of T-705, suggesting the therapeutic advantage of influenza complicated with bacterial pneumonia.

In conclusion, influenza virus infection is modified by trypsin, and T-705 inhibited both intracellular viral RNA production and extracellular virus production 10,000 and 10 times more strongly, respectively, than GS 4071. The powerful anti-influenza activity of T-705 (favipiravir) was not affected by trypsin, indicating its beneficial characteristics as an anti-influenza drug. 
Acknowledgments. We thank Dr. Takehiro Himaki and Mrs. Miho Himaki for their helpful assistance and discussion and Ms. Katherine Ono for her editorial assistance. This work was partly supported by a Grant-in-Aid for Scientific Research (25293108, 25461508) from the Ministry of Education, Culture, Sports, Science and Technology, Japan, and Toyama Chemical Co. Ltd.

\section{References}

Bisno AL, Griffin JP, Van Epps KA, Niell HB, Rytel MW (1971): Pneumonia and Hong Kong influenza: a prospective study of the 1968-1969 epidemic. Am. J. Med. Sci. 261, 251-263. https://doi.org/10.1097/00000441-197105000-00004

Daikoku T, Yoshida Y, Okuda T, Shiraki K (2014): Characterization of susceptibility variants of influenza virus grown in the presence of T-705. J. Phamacol. Sci. 126, 281-284. https:// doi.org/10.1254/jphs.14156SC

Furuta Y, Takahashi K, Fukuda Y, Kuno M, Kamiyama T, Kozaki K, Nomura N, Egawa H, Minami S, Watanabe Y, Narita $\mathrm{H}$, Shiraki K (2002): In vitro and in vivo activities of anti-influenza virus compound T-705. Antimicrob. Agents Chemother. 46, 977-981. https://doi.org/10.1128/ AAC.46.4.977-981.2002

Furuta Y, Takahashi K, Kuno-Maekawa M, Sangawa H, Uehara S, Kozaki K, Nomura N, Egawa H, Shiraki K (2005): Mechanism of action of T-705 against influenza virus. Antimicrob. Agents Chemother. 49, 981-986. https://doi. org/10.1128/AAC.49.3.981-986.2005

Furuta Y, Takahashi K, Shiraki K, Sakamoto K, Smee DF, Barnard DL, Gowen BB, Julander JG, Morrey JD (2009): T-705 (favipiravir) and related compounds: Novel broad-spectrum inhibitors of RNA viral infections. Antiviral Res. 82, 95-102. https://doi.org/10.1016/j.antiviral.2009.02.198

Jin Z, Smith LK, Rajwanshi VK, Kim B, Deval J (2013): The ambiguous base-pairing and high substrate efficiency of T-705 (Favipiravir) Ribofuranosyl 5'-triphosphate towards influenza A virus polymerase. PLoS One 8, e68347. https:// doi.org/10.1371/journal.pone.0068347

Kido H, Yokogoshi Y, Sakai K, Tashiro M, Kishino Y, Fukutomi A, Katunuma N (1992): Isolation and characterization of a novel trypsin-like protease found in rat bronchiolar epithelial Clara cells. A possible activator of the viral fusion glycoprotein. J. Biol. Chem. 267, 13573-13579.

Kiso M, Takahashi K, Sakai-Tagawa Y, Shinya K, Sakabe, S, Le QM, Ozawa M, Furuta Y, Kawaoka Y (2010): T-705 (favipiravir) activity against lethal H5N1 influenza A viruses. Proc. Natl. Acad. Sci. USA 107, 882-887. https://doi. org/10.1073/pnas.0909603107

Kurokawa M, Imakita M, Kumeda CA, Shiraki K (1996): Cascade of fever production in mice infected with influenza virus. J. Med. Virol. 50, 152-158. https://doi. org/10.1002/(SICI) 1096-9071(199610)50:2<152::AIDJMV8>3.0.CO;2-9

Kurokawa M, Tsurita M, Brown J, Fukuda Y, Shiraki K (2002): Effect of interleukin-12 level augmented by Kakkon-to, a herbal medicine, on the early stage of influenza infection in mice. Antiviral Res. 56, 183-188. https://doi.org/10.1016/ S0166-3542(02)00104-3

Kurokawa M, Watanabe W, Shimizu T, Sawamura R, Shiraki K (2009): Modulation of cytokine production by 7-hydroxycoumarin in vitro and its efficacy against influenza infection in mice. Antiviral Res. 85, 373-380. https://doi. org/10.1016/j.antiviral.2009.11.001

Kurokawa M, Watanabe W, Shimizu T, Sawamura R, Shiraki K (2010): Modulation of cytokine production by 7-hydroxycoumarin in vitro and its efficacy against influenza infection in mice. Antiviral Res. 85, 373-380. https://doi. org/10.1016/j.antiviral.2009.11.001

Peltola VT, Murti KG, McCullers JA (2005): Influenza virus neuraminidase contributes to secondary bacterial pneumonia. J. Infect. Dis. 192, 249-257. https://doi. org/10.1086/430954

Sangawa H, Komeno T, Nishikawa H, Yoshida A, Takahashi K, Nomura N, Furuta Y (2013): Mechanism of action of T-705 ribosyl triphosphate against influenza virus RNA polymerase. Antimicrob. Agents Chemother. 57, 52025208. https://doi.org/10.1128/AAC.00649-13

Schwarzmann SW, Adler JL, Sullivan RJ Jr., Marine WM (1971): Bacterial pneumonia during the Hong Kong influenza epidemic of 1968-1969. Arch. Intern. Med. 127, 1037-1041. https://doi.org/10.1001/archinte.127.6.1037

Sidwell RW, Barnard DL, Day CW, Smee DF, Bailey KW, Wong MH, Morrey JD, Furuta Y (2007): Efficacy of orally administered T-705 on lethal avian influenza A (H5N1) virus infections in mice. Antimicrob. Agents Chemother. 51, 845-851. https://doi.org/10.1128/AAC.01051-06

Smee DF, Hurst BL, Egawa H, Takahashi K, Kadota T, Furuta Y (2009): Intracellular metabolism of favipiravir (T-705) in uninfected and influenza A (H5N1) virus-infected cells. J. Antimicrob. Chemother. 64, 741-746. https://doi. org/10.1093/jac/dkp274

Takahashi K, Furuta Y, Fukuda Y, Kuno M, Kamiyama T, Kozaki K, Nomura N, Egawa H, Minami S, Shiraki K (2003): In vitro and in vivo activities of T-705 and oseltamivir against influenza virus. Antivir. Chem. Chemother. 14, 235-241. https://doi.org/10.1177/095632020301400502

Tashiro M, Ciborowski P, Klenk HD, Pulverer G, Rott R (1987a): Role of Staphylococcus protease in the development of influenza pneumonia. Nature 325, 536-537. https://doi. org/10.1038/325536a0

Tashiro M, Ciborowski P, Reinacher M, Pulverer G, Klenk HD, Rott R (1987b): Synergistic role of staphylococcal proteases in the induction of influenza virus pathogenicity. Virology 157, 421-430. https://doi.org/10.1016/00426822(87)90284-4

Treanor JJ (2005): Influenza virus. In Mandell GL, Dolin R (Ed.): Principles and Practice of Infectious Diseases. Churchill Livingstone, Philadelphia, pp. 2060.

Tsurita M, Kurokawa M, Imakita M, Fukuda Y, Watanabe Y, Shiraki K (2001): Early augmentation of interleukin (IL)-12 level in the airway of mice administered orally with clarithromycin or intranasally with IL-12 results in alleviation of influenza infection. J. Pharmacol. Exp. Ther. 298, 362-368. 